\title{
'||||||||||||||||||||||||||||||||||||||||||||||||||||||||||||||||||.
}

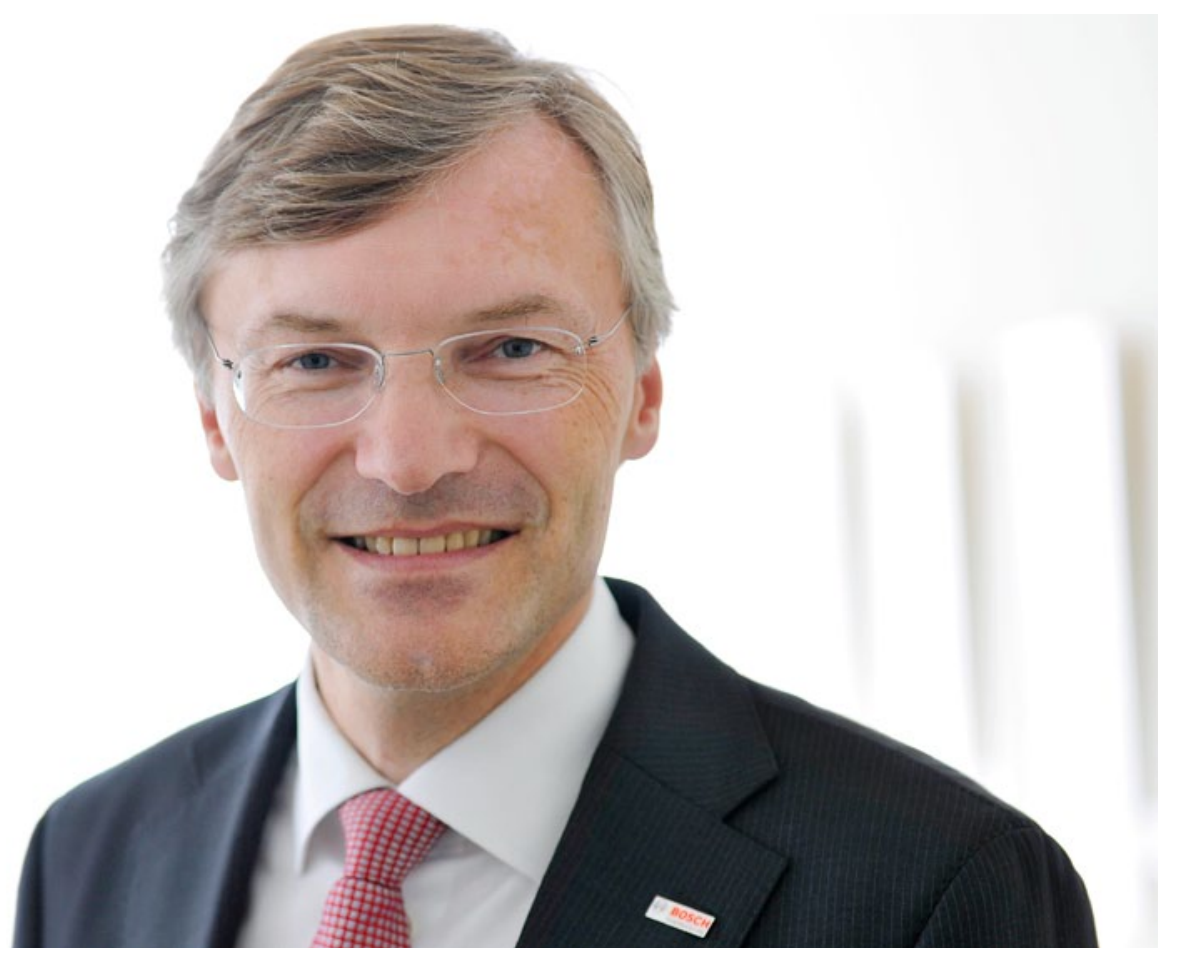

WOLF-HENNING SCHEIDER

Geschäftsführer der Robert Bosch GmbH und Sprecher des Unternehmensbereichs Kraftfahrzeugtechnik

\section{VORFAHRT FÜR DIE SICHERHEIT}

Die erfreuliche Nachricht vorneweg: Die Zahl der Verkehrstoten in Europa ist seit dem Jahr 2000 um über die Hälfte auf derzeit rund 26.000 gesunken. Einen wesentlichen Anteil daran haben aktive Sicherheitssysteme, die von Zulieferern und Automobilherstellern immer weiter perfektioniert wurden. Die schlechte Nachricht ist jedoch: Weltweit steigt die Zahl durch die zunehmende Mobilisierung in den aufstrebenden Ländern weiter an. So ist das Risiko, durch einen Verkehrsunfall ums Leben zu kommen, in Afrika und Asien rund doppelt so hoch wie in Europa.

Mehr als eine Million Verkehrstote jedes Jahr auf der Erde sind nicht akzeptabel. Weltweit streben daher immer mehr Regierungen, Verbände und die Automobilindustrie nach einem Straßenverkehr ohne Tote - der Vision Zero. Fahrzeughersteller und Zulieferer werden mit immer umfassenderen technischen Lösungen maßgeblich helfen, dieses Ziel zu erreichen. Der Weg dahin ist vielfältig und muss an die lokalen Gegebenheiten angepasst sein. Zum Beispiel Indien: Dort allein verloren 2012 rund 138.000 Menschen ihr Leben im Straßenverkehr. Die meisten der Verunglückten saßen gar nicht in einem Auto. Es waren Fußgänger oder Zweiradfahrer. Für die dortigen Motorräder hat Bosch ein besonders preiswertes ABS entwickelt. Es regelt das Vorderrad und kann allein außerhalb geschlossener Ortschaften jeden dritten Unfall mit Personenschaden verhindern. Wir haben damit einen sehr wirksamen und gleichermaßen bezahlbaren Hebel für deutlich mehr Sicherheit gefunden.
Aber auch von unseren anderen Sicherheitsprodukten für den Pkw gibt es kostenoptimierte Varianten. Das Basis-Steuergerät für Rückhaltesysteme wurde in China entwickelt und wird dort auch gefertigt. Es nutzt konsequent Standard-Bauteile und spart Kosten durch eine geringere Zahl an Endstufen. Sein niedriger Preis erleichtert die Marktdurchdringung erheblich.

Wie aber geht es in den etablierten Märkten weiter? Den nächsten Schub für mehr Verkehrssicherheit bringt die Fahrerassistenz. Bosch und die ganze Autoindustrie entwickeln daher intensiv Funktionen, die den Fahrer in kritischen und auch eintönigen Situationen immer umfassender unterstützen. Denn dessen falsches Verhalten spielt in nahezu $90 \%$ aller Unfälle eine entscheidende Rolle. Zudem treiben neue Euro-NCAP-Bewertungsregeln die Verbreitung vorausschauender Notbremssysteme und Spurhalteassistenten voran. Auswertungen der Gidas-Unfalldatenbank zeigen zum Beispiel, dass die automatische Notbremsung in Deutschland jeden fünften Unfall mit Personenschaden verhindern kann. Gleiches gilt für einen Abbiege- und Kreuzungsassistenten. Ein weiteres, riesiges Potenzial für mehr Sicherheit und auch Komfort steckt schließlich im automatisierten Fahren. Zunächst beschränkt auf niedrigere Geschwindigkeiten im Stau werden wir bereits im kommenden Jahrzehnt das hoch- und vollautomatische Fahren zumindest auf Autobahnen mit Reisegeschwindigkeit erleben. So werden wir der Vision Zero einen weiteren großen Schritt näherkommen. 